\title{
MUSULMANAS Y FEMINISTAS: ¿UNA ECUACIÓN IMPOSIBLE?
}

\section{Muslims and feminists: an impossible equation?}

\author{
Carmen Vidal Valiña \\ carmenmarinavidal@hotmail.com \\ Investigadora independiente - España
}

Recibido: 27-02-2017

Aceptado: 03-06-2017

\section{Resumen}

Los feminismos islámicos nacieron en los años noventa del siglo XX y desde entonces han sido objeto de severas críticas por parte de quienes consideran que no es posible luchar por los derechos de las mujeres desde las propias creencias. Frente a sus opositores, académicas y activistas abogan por la hermenéutica coránica como herramienta para desvelar las potencialidades que el texto sagrado ofrece para la igualdad. Su discurso es, además, un ataque directo a las concepciones más tradicionales del feminismo occidental y sus representaciones a menudo estereotipadas de las musulmanas.

Palabras Clave: Islam, religión, feminismo islámico, feminismos decoloniales, hermenéutica coránica.

\section{Abstract}

Islamic feminisms were born in the 90's and since then they have been subject to criticism by those who believe that it is not possible to fight for women's rights in the framework of a religion. However, the scholars and activists of the Islamic feminisms advocate for the Koranic hermeneutics as a tool to unveil the potential that the sacred text offers for equality. Their discourse is also a direct attack to the most traditional conceptions of Western feminism and its often-stereotyped representations of Muslim women.

Keywords: Islam, religion, Islamic feminism, decolonial feminism, Koranic hermeneutics. 


\section{Un binomio marcado por la controversia}

Religión y feminismo configuran un binomio que genera agrias polémicas. ¿Es posible defender los derechos de las mujeres partiendo de convicciones con base patriarcal? ¿Puede ser la creencia en un Dios una herramienta válida para luchar por los derechos de las mujeres en contextos en los que dicha creencia permea en diversos ámbitos de la sociedad? Cuando la religión de la que se habla es el Islam, la ecuación se complica todavía más. Parece imposible, en estos tiempos, aproximarse al mundo musulmán desde una perspectiva objetiva o, cuanto menos, descargada de estereotipos y asunciones previas ${ }^{1}$. Por eso, en un contexto como el español, sigue causando estupor entre muchas personas hablar de feminismo islámico. Tomemos como ejemplo una anécdota de plena actualidad: Sirin Adlbi Sibai, politóloga de origen sirio, comenzó a escribir su tesis, recientemente presentada en forma de libro bajo el título La cárcel del feminismo, después de que un profesor le preguntase para qué quería escribir algo así si llevaba hiyab. Puede parecer un ejemplo extremo, pero las asociaciones de muchas personas que en Occidente siguen considerando que una mujer con velo islámico es sumisa, fanática o dependiente de los hombres siguen estando a la orden del día. Todo ello por no hablar de las invasiones de Iraq o Afganistán que inauguraron el siglo XXI, presentadas, por continuar con el vocabulario religioso, como "mesiánicas" operaciones de liberación de las mujeres locales. Lejos de ser una crítica procedente solo del ámbito occidental, desde el contexto árabo-musulmán son también muchas quienes abogan porque la religión no se entrometa en el ámbito del feminismo. Una de ellas es la argelina Wassyla Tamzali, abogada, escritora y militante conocida por su acérrima defensa del laicismo, quien fue radical al respecto en una reciente entrevista: "Es incompatible ser feminista y llevar velo" (Pita, 2016)2.

Pero, ¿cuál es el origen de la corriente en la que se centrará este artículo? El feminismo islámico surge a finales de los años noventa del siglo XX en un contexto marcado por la redefinición de la propia idea de feminismo. Los que se han denominado, de acuerdo con la autora o la corriente, feminismos decoloniales, postcoloniales, nómadas, desde los márgenes o de la tercera ola tienen en común su crítica a un feminismo que, pretendiendo presentarse como universal, era en el fondo profundamente discriminatorio, por tomar como sujeto de estudio únicamente a las mujeres blancas, de clase media, occidentales, laicas. Estas nuevas corrientes introducen en el debate la raza, la clase social, la etnia y, en el caso de los feminismos islámicos, la religión. Lo que buscan, en suma, es demostrar que no existe un solo modelo de mujer, sino las mujeres, en plural, y que cada una de ellas, dependiendo de su contexto, prioridades o preocupaciones, puede desarrollar su propio modelo de lucha. Los feminismos desde los

\footnotetext{
${ }^{1}$ Sobre esos estereotipos que rodean la cobertura mediática del Islam y sus mujeres desde hace décadas reflexioné en mi ensayo El mundo árabo-islámico como ellas nos lo contaron, publicado por Clave Intelectual en 2016.

${ }^{2}$ Así lo manifestó en su entrevista a El País realizada el 10 de febrero de este mismo año (Pita, 2016).
} 
márgenes suponen, pues un cuestionamiento interno a las teorías vigentes hasta ese momento y ponen sobre el tapete cuestiones vinculadas a la identidad, la subjetividad y las políticas de representación. De este modo, musulmanas, junto con negras o indígenas, pasan a convertirse en sujetos y protagonistas de su propia historia, dejando de ser objetos de estudio, como hasta ese momento habían sido mayoritariamente consideradas.

En este sentido, se exige explícitamente el reconocimiento de la alteridad, de otros modos de ser mujer, lo que inevitablemente conlleva una cierta crisis y replanteamiento del feminismo tal y como se había entendido hasta el momento. Se considerará que la identidad occidental (europeonorteamericana) se ha construido creando una alteridad excluyente, en la que todo lo que no es europeo o norteamericano se construye negativamente. En suma, las feministas blancas occidentales han cultivado, en base a las variables de la raza o la laicidad, unos mecanismos de exclusión que lejos de ser inocentes, perpetúan nociones de poder y superioridad. A diferencia del pensamiento único que había dominado las corrientes blancas hegemónicas, todos estos movimientos abogan por un sujeto múltiple y están, por tanto, atravesados por la diferencia, que se entiende como la posibilidad de definirse desde la propia subjetividad. Es en este contexto polémico y apasionante en el que surgen los feminismos islámicos.

Ello no implica que antes de los años noventa del siglo XX las mujeres musulmanas no hubiesen batallado por sus derechos: por el contrario, la resistencia femenina vinculada a las protestas anticolonialistas tiene una larga tradición en el mundo araboislámico. Por citar solamente algunos ejemplos, las egipcias desempeñaron un papel determinante en el levantamiento contra los británicos durante los primeros años del siglo pasado, y en los años treinta y cuarenta, organizaciones de mujeres árabes se implicaron activamente con la causa palestina, lideradas por Huda Shaarawi, periodista y una de las pioneras del movimiento feminista egipcio, fundadora de la Unión Feminista Egipcia. Durante la época del socialismo árabe, activas organizaciones de mujeres batallaron por sus derechos en Afganistán o Iraq. Las revueltas árabes, entre 2011 y 2013, volvieron a poner de manifiesto que, lejos de la imagen de sumisión y pasividad con la que se las inviste a menudo en Occidente, las mujeres de Oriente Medio y Norte de África tienen mucho que decir en el ámbito público de sus respectivas sociedades.

Teniendo en cuenta todo ello, y aunque pensadoras como Bint al-Sati ya releyeron hace décadas el Corán para adaptarlo a su época y contribuir a la emancipación de las musulmanas, no es hasta la década de los noventa del siglo XX cuando se comienza a emplear el término del “feminismo musulmán” de una manera más habitual. Así lo hicieron el estudioso saudí Mai Yamani en su libro El feminismo y el Islam (1996), la activista y periodista sudafricana Shamima Shaikh en sus discursos y artículos de la misma década, las iraníes que escriben en la revista Zanan, fundada en 1992, o los académicos Yesim Arat, Feride Acar y Gole Nilufer, que recurren a este término para referirse a un nuevo paradigma feminista que estaba surgiendo en esos momentos en Turquía. A mediados de la década de los noventa, el término había triunfado y se había distribuido por diversos rincones de la umma, la comunidad de creyentes en el Islam, para 
definir a una nueva corriente de lucha por los derechos de la mujer que se prolonga hasta la actualidad.

\section{La religión como base y herramienta de lucha}

Los feminismos islámicos toman como punto de partida un elemento que los hace quebradores respecto al feminismo blanco hegemónico, laico en su concepción: el Islam. Ciertamente, en nuestro contexto occidental siguen siendo mayoría quienes consideran incompatible religión y feminismo, como si fuesen propuestas antagónicas e irreconciliables, argumentando que el Islam es una ideología de obediencia que nunca podrá contribuir a la liberación femenina. ¿Cómo combina el feminismo islámico estas dos esferas? Lo hace empleando una herramienta, la hermenéutica coránica, que le permite releer el texto sagrado para despojarlo de las erróneas interpretaciones que, durante siglos, lo han empleado como base de la desigualdad entre sexos. En este sentido, las feministas musulmanas consideran que el propio Corán lleva en su seno un elemento emancipador innegable que contribuirá a la liberación de las musulmanas. Conviene aclarar este punto, pues en efecto, son todas las musulmanas sus destinatarias, independientemente del país en el que se ubiquen. En pleno siglo XXI, con un Islam expandido por los cinco continentes, con segundas y terceras generaciones de emigrantes en Francia o Alemania, conversos en España e hijos de matrimonios mixtos en Bélgica o Estados Unidos, resulta enormemente reduccionista seguir con la errónea asociación entre Islam y mundo árabe. De hecho, buena parte de las principales feministas islámicas desarrollan su trabajo en Estados Unidos. El feminismo islámico, pues, se dirige tanto a las creyentes de Oriente Medio y Norte de África como a las que se reparten por el resto del mundo, sean musulmanas de nacimiento o no. En el caso español, de hecho, los cuatro Congresos Internacionales sobre Feminismo Islámico que se celebraron hasta el año 2010 pusieron de manifiesto la necesidad de establecer estrategias específicas para las musulmanas que habitan en territorios donde el Islam no es la religión mayoritaria, dando respuesta a sus problemas y retos específicos (Prado, 2010) ${ }^{3}$. Teniendo en cuenta que el feminismo islámico concede una importancia esencial a la justicia tanto en el ámbito de las propias relaciones de género como en el social en su sentido más amplio, directamente se interesará por cuestiones de pluralismo religioso o valores democráticos que puedan surgir en cualquiera de los países en los que trabaja. Las feministas islámicas son, pues, en sí mismas, un claro ejemplo de puente entre Oriente y Occidente, que demuestra la creciente

\footnotetext{
${ }^{3}$ Abdennur Prado hablaba de este evento único para el feminismo islámico español en su blog, el 27 de septiembre de 2010, unos días antes del inicio del Congreso: https://abdennurprado.wordpress.com/2010/10/10/826/ [10/01/2017].
} 
variedad de un Islam en cambio que ya no puede por más tiempo permanecer ajeno al papel esencial que las mujeres desempeñan dentro de él.

Además de orígenes nacionales muy diversos, también son variados sus perfiles: desde las puramente academicistas hasta las que conceden una especial importancia al ámbito del activismo. Las hay, como la profesora y académica estadunidense Amina Wadud, que escandalizaron al dirigir la oración del viernes, renegociando directamente el papel de las musulmanas en la esfera pública; otras, como la educadora comunitaria y periodista chilena Vanessa Rivera de la Fuente, abordan sin tapujos la defensa de la homosexualidad dentro del Islam, y extienden su mensaje a diversas áreas de Latinoamérica gracias a las redes sociales; desde Marruecos, la médica Asma Lamrabet aboga por redefinir ciertos aspectos discriminatorios de los Códigos de Familia recurriendo a la relectura de diversas aleyas, los versículos del Corán 4 . Las estrategias y los recorridos vitales de las feministas islámicas son, pues, enormemente variados, pero una característica que las une a todas: su aproximación feminista se realiza en el marco de la religión. De hecho, su presupuesto básico es que las mejoras en la situación de las mujeres musulmanas han de estar legitimadas por el Corán.

En consonancia con todo ello, el Corán se convierte en el texto de referencia básico: conviene releerlo de nuevos modos, despojándolo de sus interpretaciones patriarcales y rescatando aquellos elementos favorables a los derechos de las mujeres. Se apuesta, por tanto, por una lucha feminista que no obligue a renunciar a las propias creencias, tal y como "exigía" el laicismo del feminismo blanco hegemónico. Lejos de considerar el Islam como una religión discriminatoria, estas pensadoras consideran que en su propio seno están las herramientas que permitirán romper con siglos de hegemonía masculina.

El hecho de que se basen en la reinterpretación del texto sagrado provoca que gran parte de las feministas islámicas posean un perfil teológico, que les permite acercarse a los significados más profundos de cada aleya. Su referencia a las fuentes del Islam (Corán y sunna) con el fin de eliminar lecturas e interpretaciones sexistas es constante, y se combina con el dominio de las ciencias islámicas y los instrumentos de las ciencias sociales. Por ello, a su vertiente de teólogas suman, según los casos, el perfil de comprometidas activistas o de sociólogas interesadas por entender el cambio de sus respectivos países. Tampoco faltan las politólogas, abogadas o hasta médicas, como la ya mencionada Asma Lamrabet.

¿Cuáles son los ejes de trabajo fundamentales a los que las feministas islámicas prestan atención a la hora de realizar su trabajo? Sin duda, la historia y su transmisión es uno de los fundamentales: implica revisar ciertos pasajes para comprobar qué otras traducciones o interpretaciones alternativas, y más proclives a los derechos de las mujeres, se podrían hacer sobre ellos. Reanalizar la historia bajo una nueva luz también supone resaltar el notable papel que varias de las mujeres de los primeros tiempos del Islam desempeñaron, y cuya actividad ha sido generalmente silenciada por los teólogos varones que se han acercado al texto sagrado. Es

\footnotetext{
${ }^{4}$ Buena parte de sus artículos académicos, así como de las entrevistas que se le han realizado, son accesibles a través de su web: http://www.asma-lamrabet.com [10/01/2017].
} 
importante, por tanto, reescribir la historia sagrada concediendo una especial importancia al poder femenino en ese contexto de los primeros años del Islam, señalando, también que ciertos aspectos que en su momento surgieron motivados por la situación femenina en el momento de la Revelación, como el reparto desigual de la herencia, no tienen ya sentido en pleno siglo XXI, en un contexto radicalmente diferente. Para Amina Wadud, el Corán se adapta al contexto de la mujer moderna tan fluidamente como se adaptó al de la comunidad musulmana original hace catorce siglos. Cualquier interpretación que lo entienda únicamente como una reproducción literal de lo establecido para la comunidad original comete una injusticia con el texto. Por el contrario, el objetivo ha de ser emular ciertos principios clave del desarrollo humano que recoge: justicia, armonía, responsabilidad moral, desarrollo..., y que son aplicables a cualquier época y lugar.

Estas autoras abogan, por tanto, por revisar ciertos aspectos a priori discriminatorios del texto sagrado a la luz de las circunstancias actuales y el papel cada vez más activo de las musulmanas en sus sociedades. Que en la antigua Arabia fuesen los hombres los detentadores del poder político y financiero no debe llevar a concluir, como por lo general se ha hecho, que siempre deben de ser los más apropiados para ejercer el liderazgo. Las capacidades de las mujeres se han visto incrementadas notablemente desde hace catorce siglos, lo que las hace estar ahora mucho más preparadas para acceder a esos puestos de responsabilidad.

Todo ello implica, por supuesto, que en esa revisión del Corán se puedan proponer adaptaciones en su estructura y contenido que despierten polémica dentro del propio mundo musulmán. Un claro ejemplo de ello es el de la profesora Ghazala Anwar, que reinterpreta las categorías de sexo en el Islam desde una visión más amplia de lo que lo hacen otras autoras y, en esa amplitud, reivindica el derecho de gays y lesbianas a poder ejercer su orientación sexual en el ámbito público y en el marco de su religión.

Considerando todo lo hasta ahora apuntado, la lengua se convierte en un elemento fundamental de reanálisis, pues permitirá esta revisión de aleyas del Corán que venimos apuntando, al tiempo que permite localizar y poner en valor otras que, pese a señalar inequívocamente la igualdad entre sexos, o quizás precisamente por ello, han sido generalmente opacadas. Se trata, en suma, de dominar la lengua original del Corán para examinar su contenido desde una nueva luz que ponga en valor sus elementos favorables a la igualdad, empleando la hermenéutica coránica como herramienta fundamental.

Jolanda Guardi y Renata Benendo (2011), en su obra Teólogas, musulmanas, feministas, distinguen cuatro enfoques básicos a la hora de aproximarse al Corán en el caso de las feministas islámicas:

1. Apologético: esta postura considera que el texto del Corán ya recoge, en sí mismo, todos los derechos necesarios para el bienestar de ambos sexos y para su igualdad. Por tanto, apuesta por una teología de la liberación femenina con el Islam como base, lo que no supone una amenaza para los sectores más tradicionales, puesto que no cuestiona en ningún momento los fundamentos de esta religión 
2. Reformista: es la tendencia con un mayor número de seguidoras, y defiende la necesidad de cuestionar las interpretaciones que hasta el momento han malinterpretado la palabra de Dios, dando lugar, en consecuencia, a una serie de ideas incorrectas sobre el lugar de la mujer en el marco de la religión musulmana

3. Transformacionista:a diferencia de la posición reformista, que lleva a cabo una nueva interpretación de las aleyas del Corán, la postura transformacionista deja intacta la tradición pero a cambio permite diversas posibilidades de modificaciones internas

4. Racionalista:considera esencial el criterio de justicia, por lo que selecciona solamente aquellos aspectos del Corán que se avienen a dicho criterio, lo que hace que se trate de una postura más polémica que las anteriores.

Guardi y Benendi (2011) distinguen una quinta categoría, que aquí sin embargo mencionaremos por separado, por entender que supone una ruptura con las señaladas hasta el momento: se trata de la que defienden aquellas que rechazan absolutamente el texto coránico en la esfera de la legislación relativa a las mujeres. Es una postura más radical, representada entre otras por Taslima Nasreen, escritora bengalí que se define a sí misma como "humanista secular", y que alcanzó fama en Occidente por su novela Lajja (Vergüenza), publicada en 1992. En ella realiza una grave y severa crítica al Islam, que le costó el exilio de su Bangladesh natal ante las amenazas de los fundamentalistas. También es la postura de la ya mencionada Wassyla Tamzali o de la egipcia Nawal al Saadawi. Ambas llevan décadas luchando contra el fundamentalismo y el machismo de sus sociedades desde postulados completamente laicos. Entre las generaciones más jóvenes, el trabajo de la libanesa Joumana Haddad es también un canto de libertad de la mujer árabe, despojada de cualquier tipo de atadura religiosa.

Más allá de la polémica en torno a la posibilidad o imposibilidad de combinar religión y feminismo, lo que sin duda el feminismo islámico plantea es una vía, propia, que choca frontalmente contra las construcciones feministas llegadas desde Occidente. Las pensadoras de esta corriente critican la creación de una imagen del Islam retrógrada y extremadamente negativa para la mujer, que no tiene en cuenta las particularidades de cada uno de los países donde se practica esta religión. El reciente libro de Sirin Adli Sibai, La cárcel del feminismo, publicado en 2016, aboga justamente en su subtítulo por un "pensamiento islámico decolonial”, poniendo de manifiesto que las corrientes hegemónicas de defensa de los derechos de las mujeres con base en Europa o Estados Unidos no son desde luego neutras: a menudo incluyen, en su seno, un modo "correcto" de ser mujer, asociando todo lo que no se corresponde con esos parámetros de laicidad o blanquitud con un estatus inferior y, por ende, subordinado. El feminismo occidental sigue en muchas ocasiones juzgando las estructuras económicas, legales, familiares y religiosas de las mujeres de todo el mundo en base a estándares que no se corresponden en muchos casos con sus realidades. Al definir otras realidades como menos válidas se las somete a un status inferior y se 
impone el desarrollo "a la occidental" como única medida. El fracaso de esa supuesta modernización en países como Iraq o Afganistán debería ser ejemplo más que suficiente para demostrar que el calco de estructuras y modelos no es válido.

Frente a esa imagen construida desde fuera durante siglos, las feministas islámicas contraponen la búsqueda de soluciones desde un marco referencial propio, que preste especial atención a la lucha contra la islamofobia y, más concretamente, la islamofobia de género, que discrimina doblemente a las musulmanas por su religión y por su sexo: no quieren ser objeto de estudio sino protagonistas de su propia historia. En ese sentido, pues, su crítica discursiva y activista es doble: al feminismo occidental y a la dominación patriarcal del Islam ${ }^{5}$.

\section{3. ¿Y en España?}

En España, el feminismo islámico ha experimentado un notable empuje en los últimos tiempos, vinculado fundamentalmente a una serie de nombres muy activos en las redes sociales, y a iniciativas colectivas que tuvieron una de sus más notables manifestaciones en los Congresos Internacionales de Feminismo Islámico, que reunieron a académicas y activistas de todo el mundo en nuestro país. Se realizaron cuatro, el último en Madrid, del 21 al 24 de octubre de 2010, recogiendo, entre sus conclusiones, aspectos globales de esta corriente, como su sustento en el principio de la justicia, que se extiende al ámbito económico, religioso y democrático, así como la consideración de que solamente teniendo en cuenta la diversidad de los distintos países podrá tener éxito su discurso. Junto a estas nociones más genéricas se apuntaban otras específicamente ligadas al marco occidental, donde se consideraba la defensa de los derechos específicos de las musulmanas en lo que se refiere al acceso al espacio público, las mezquitas y las instancias de poder, en igualdad de condiciones con los hombres.

La profesora Ndaye Andújar, la periodista Laure Rodríguez Quiroga y Abdennur Prado, fundador y presidente de la Junta Islámica Catalana desde el año 2005 hasta su disolución el año 2011, son tres de los nombres más destacados del feminismo islámico con raíces españolas, siendo, además, perfiles muy activos a través de sus blogs y artículos. La voz de la joven de origen sirio Wadi N-Daghestani resuena con fuerza cuando señala en sus redes sociales, sin ambages, que se puede ser musulmana y feminista y que quedan todavía muchos estereotipos por desmontar. A todos estos nombres se podrían sumar exégetas como Maite Carbajo o Carmen del Río. La lista, sin duda, es mucho más amplia y va añadiendo nombres e iniciativas cada poco tiempo. Internet y, de forma particular, las redes sociales, se han mostrado como potentísimas herramientas para dar a conocer el feminismo islámico español y sus iniciativas y problemas

\footnotetext{
${ }^{5}$ Intervención de Hindi, Nadia. "Taller feminismos decoloniales". Granada, ErranT, 6 y 7 de mayo de 2016. No publicada.
} 
específicos. Así lo hacen la revista Alkalima $^{6}$, que presta una especial atención a la espiritualidad, la interpretación coránica y la deconstrucción del patriarcado, siempre desde una mirada decolonial, o Red Musulmanas ${ }^{7}$, una plataforma que practica el activismo online para mostrar la diversidad de perfiles de las musulmanas que existen hoy en día, contribuyendo a desmontar los estereotipos existentes sobre ellas.

El feminismo islámico originado en España, al igual que el que se practica en otros países occidentales, tiene que atender a cuestiones específicas que no se plantean en sociedades de mayoría musulmana: desde la islamofobia latente o velada hasta la cuestión del hiyab, que se intenta a menudo presentar como fuente de conflicto y diferencia. Los ataques terroristas del 11$\mathrm{S}$ y, más recientemente, los ataques de corte yihadista que se han venido sucediendo sobre suelo europeo han marcado un punto de inflexión en una relación ya de por sí tirante entre el Islam y los países occidentales. La idea de amenaza y violencia inherente no sólo a los Estados de mayoría musulmana, sino también a los musulmanes residentes en Europa o Estados Unidos, se extendió tras esos sucesos y dio lugar en ocasiones al repunte de la islamofobia. Las mujeres, en este sentido, se instrumentalizan a menudo como ejemplo de a qué extremos puede conducir el fanatismo islámico, de ahí que el papel de las feministas musulmanas sea tan relevante en el contexto actual.

\section{BIBLIOGRAFÍA}

- Adlbi Sibai, Sirin (2016): La cárcel del feminismo. Hacia un pensamiento islámico decolonial. Tres Cantos: Madrid.

- Guardi, Jolanda y Bedendo, Renata (2011): Teólogas, musulmanas, feministas. Madrid: Narcea, S.A. de Ediciones.

- Pita, Antonio (2016): "Wassyla Tamzali: es incompatible ser feminista y llevar velo". Entrevista a Wassyla Tamzali. En: El País, 23 de diciembre de 2016. Disponible en: http://elpais.com/elpais/2016/12/12/planeta_futuro/1481544684_276839.html [07/01/2017].

- Prado, Abdennur (2010): “IV Congreso Internacional de Feminismo Islámico". En: Abdennur Prado, 10 de octubre de $2010 . \quad$ Disponible en: https://abdennurprado.wordpress.com/2010/10/10/826/ [07/01/2017].

- Vidal Valiña, Carmen Marina (2016): El mundo árabo-islámico como ellas nos lo contaron. Madrid: Clave Intelectual.

- Yamani, Mai (1996): Feminism and Islam. Legal and Literary Perspectives. New York: New York University Press.

${ }^{6}$ Disponible en: www.alkalima.es [07/01/2017].

${ }^{7}$ Disponible en: http://redmusulmanas.org/ [07/01/2017]. 